Al-Khwarizmi: Jurnal Pendidikan Matematika dan Ilmu Pengetahuan Alam

Oktober-2019, Vol.7, No.2, hal.113-122

$\operatorname{ISSN}(P): 2337-7666 ; \operatorname{ISSN}(E): 2541-6499$

https://ejournal.iainpalopo.ac.id/index.php/al-khwarizmi

DOI: http://dx.doi.org/10.24256/jpmipa.v7i2.1024

\title{
Analisis Simulasi Sirkulasi Udara Dalam Optimasi Teknologi Pascapanen Buah Berdasarkan Prosedur Pengemasan
}

\author{
${ }^{1}$ Arif Fatahillah, ${ }^{2}$ Soleh Chudin, ${ }^{3}$ Dafik \\ ${ }_{1}^{1}$ Program Studi Pendidikan Matematika FKIP Universitas Jember \\ Jalan Kalimantan 37 Jember \\ Email: arif.fkip@unej.ac.id
}

Article History:

Received: 07-08-2019; Received in Revised: 01-09-2019; Accepted: 29-10-2019

\begin{abstract}
Indonesia is a producer of various types of fruit. Production and area of plantations tend to increase every time. However, its quality and safety still need attention. In general, the low quality of fruit is caused by postharvest management, one of which is in the packaging process. Specific temperatures and pressures will affect air circulation in the fruit packaging container. Besides, the good packaging design of containers will result in proper air circulation. The finite volume method is used to analyze air circulation in the optimization of postharvest technology based on packaging procedures. The results showed the higher the incoming air pressure, the temperature of the air formed in the packaging container would be even higher. The air holes with the up and down position help in the process of air circulation more evenly. More air holes will increase the temperature of the air inside the packaging container.
\end{abstract}

Keywords: Finite Volume Method; Air Flow; Temperature.

\begin{abstract}
Abstrak
Indonesia merupakan penghasil beragam jenis buah. Produksi dan luas pertanaman cenderung meningkat setiap waktu. Namun demikian mutu dan keamanannya masih perlu mendapat perhatian. Secara umum, rendahnya mutu buah disebabkan oleh pengelolahan pascapanen, salah satunya dalam proses pengemasan. Suhu dan tekanan tertentu akan mempengaruhi sirkulasi udara di dalam wadah kemasan buah. Selain itu, desain wadah kemasan yang baik akan mengakibatkan sirkulasi udara yang baik. Metode volume hingga digunakan untuk menganalisis sirkulasi udara dalam optimasi teknologi pascapanen buah berdasarkan prosedur pengemasan. Hasil penelitian menunjukkan semakin besar tekanan udara yang masuk maka suhu udara yang terbentuk di dalam wadah kemasan akan semakin besar. Posisi lubang udara dengan posisi atas dan bawah membantu dalam proses sirkulasi udara yang lebih merata. Semakin banyak lubang udara akan meningkatkan suhu udara di dalam wadah pengemasan.
\end{abstract}

Kata Kunci: Metode Volume Hingga; Sirkulasi Udara; Teknologi Pascapanen.

(CAl-Khwarizmi: Jurnal Pendidikan Matematika dan IImu Pengetahuan Alam. This is an open access article under the CC BY-SA 4.0 license (https://creativecommons.org/licenses/by-sa/4.0/). 


\section{Pendahuluan}

Matematika merupakan ilmu yang mendasari pengembangan ilmu-ilmu lainnya. Hal ini dikarenakan pada sebagian disiplin ilmu tertentu, matematika sering digunakan untuk membantu dalam menyelesaikan berbagai permasalahan yang khususnya berkaitan dengan komputasi atau perhitungan. Selain itu, konsep dan prinsip matematika banyak digunakan dalam kehidupan sehari-hari. Salah satunya dalam bidang pertanian khususnya pada teknologi pascapanen buah.

Indonesia merupakan negara berkembang dengan jumlah penduduk sebagian besar menggantungkan nasibnya bekerja di sektor pertanian khususnya dalam bidang pertanian buah. Kehadiran buah sebagai salah satu menu sehari-hari yang merupakan sumber serat pangan untuk kesehatan. Buah-buahan dibutuhkan oleh manusia untuk pemenuhan gizi yang seimbang. Pada umumnya buah banyak mengandung vitamin dan mineral-mineral tertentu khususnya vitamin A (karotene), serat (dietary fiber), gula dan pemenuhan vitamin $\mathrm{C}$ (asam askorbat) yang tidak dapat diproduksi oleh tubuh¹.

Buah-buahan merupakan salah satu komoditas hortikultura yang memegang peranan penting bagi pembangunan pertanian di Indonesia, dewasa ini holtikultura banyak diberi perhatian pemerintah untuk digalakkan dan dikembangkan secara luas. Produk buah-buahan di negara ini sebenarnya memiliki pangsa pasar yang cukup besar di dalam negeri dan peluang ekspor yang baik yang memungkinkan sebagai devisa negara non migas.

Buah di Indonesia terdiri atas buah klimaterik, yaitu buah yang mengalami lonjakan produksi CO2 dan produksi etilen setelah pascapanen yang memutuhkan ruang pendingin untuk optimasi pascapanen dan ada juga buah non klimaterik yaitu buah yang tidak mengalami lonjakan produksi CO2 dan produksi etilen, salah satu buah non klimaterik adalah buah jeruk dimana karakteristiknya mudah bertahan dalam luar pendingin setelah pascapanen. Penerapan teknologi produksi dan penanganan pascapanen buah yang tidak memadai akan mengakibatkan inkonsistensi mutu dengan tingkat kehilangan yang tinggi.

FAO menandai, masalah utama penanganan pascapanen buah antara lain adalah: 1) waktu pemanenan yang tidak tepat, 2) over packing dan cara mengemas yang tidak tepat, 3) kerusakan fisik akibat benturan dan penanganan yang kasar, dan 4) perubahan kimia selama proses

1 Siswadi -, "Penanganan Pasca Panen Buah-Buahan Dan Sayuran," Innofarm:Jurnal Inovasi Pertanian 6, no. 1 (September 1, 2012), http://ejurnal.unisri.ac.id/index.php/innofarm/article/view/250. 
penyimpanan ${ }^{2}$. Faktor tersebut mengakibatkan rendahnya status jaminan keamanan aneka buah di Indonesia yang ditandai dengan tingkat kontaminasi yang tinggi ${ }^{3}$.

Proses pengemasan merupakan salah satu prosedur pascapanen pada buah, dalam penelitian A. Ambaw menjelaskan buah pasca panen masih dalam kondisi baik dan setelah mengalami proses penyimpanan pada ruang pendingin menjadi rusak, hal ini dikarenakan dalam pengemasan dan aliran udara pendingin yang buruk dapat menyebabkan kerusakan terhadap buah pascapanen ${ }^{4}$. Selain itu, tidak semua para petani memiliki ruang pendingin untuk menyimpan buah pascapanen sehingga pada penelitian ini dikembangkan model baru pada proses pengemasan diluar ruang pendingin agar buah pascapanen tetap baik dalam berbagai macam kondisi. Wadah pengemasan juga didesain agar dapat digunakan untuk menjaga kondisi buah pascapanen, karena wadah pengemasan menjadi salah satu hal yang mempengaruhi aliran udara agar dapat merata keseluruh bagian. Pada penelitian ini akan digunakan wadah pengemasan berbahan kayu. Pada penelitian lain yang dilakukan oleh Andriani menyatakan bahwa semakin lama waktu yang digunakan maka suhu dinding semakin lebih tinggi daripada suhu lingkungan yang berakibat buah cepat matang dan busuk ${ }^{5}$, tetapi untuk letak lubang udara, banyak lubang udara serta tekanan awal udara tidak diteliti. Dalam penelitian lain yang dilakukan oleh Trisnawati, $\mathrm{W}$ didapatkan hasil bahwa penggunaan kemasan besek dalam bentuk tandan mampu mempertahankan kesegaran buah selama 9 hari masa simpan ${ }^{6}$ Penelitian ini tidak menjelaskan secara detal bagaimana bentuk kemasan, ukuran dan lainlain. Oleh karena itu dalam penelitian ini akan diteliti terkait faktor-faktor tersebut yaitu letak lubang udara, banyak lubang udara, bentuk dan ukuran kemasan yang akan dipakai sebagai bahan kemasan buah tersebut.

\footnotetext{
${ }^{2}$ Food and Agriculture Org, Food Loss Preventation in Perishable Crops (Rome: The Food and Agriculture Organization, 1981).

${ }^{3}$ Miskiyah Miskiyah, Christina Winarti, and Wisnu Broto, "Kontaminasi Mikotoksin Pada Buah Segar Dan Produk Olahannya Serta Penanggulangannya," Jurnal Penelitian Dan Pengembangan Pertanian 29, no. 3 (December 5, 2016): 79-85, https://doi.org/10.21082/jp3.v29n3.2010.p79-85.

4 Alemayehu Ambaw et al., "The Use of CFD to Characterize and Design Post-Harvest Storage Facilities: Past, Present and Future," Computers and Electronics in Agriculture 93 (April 1, 2013): 184-94, https://doi.org/10.1016/j.compag.2012.05.009.

${ }^{5}$ Filli Andriani, Riswanti Sigalingging, and Saipul Bahri Daulay, "Kajian Aliran Udara Dan Suhu Pada Kemasan Komoditi Pepaya (Carica Papaya L) Menggunakan Teknik Computational Fluid Dynamics (CFD) (Study of Airflow and Temperature at Papaya Commodity Packaging Using Computational Fluid Dynamics (CFD) Technique)," Jurnal Rekayasa Pangan Dan Pertanian 6, no. 2 (September 27, 2018): 320-326-326.

${ }^{6}$ W. Trisnawati and Rubiyo, "Pengaruh Penggunaan Kemasan Dan Lama Penyimpanan Terhadap Mutu Buah Salak Bali,” Jurnal Pengkajian Dan Pengembangan Teknologi Pertanian 7 , no. 1 (August 11, 2014), https://doi.org/10.21082/jpptp.v7n1.2004.p\%p.
} 
Dalam penelitian ini akan dibangun suatu model persamaan diferensial matematika berdasarkan rumus fisika yaitu persamaan kekekalan energi dan persamaan momentum. Penelitian ini dilakukan untuk mengembangkan model sirkulasi udara pada pengemasan produk pascapanen buah di luar ruang pendingin, selain itu untuk mengetahui desain wadah pengemasan produk pascapanen buah yang baik dan memiliki sirkulasi udara turbulen, serta mengetahui efektivitas metode voulume hingga dalam menganalisis sirkulasi aliran udara pada pengemasan produk pascapanen di luar ruang pendingin. Model yang digunakan dalam penelitian proses pengemasan buah ini adalah seperti berikut :
1. $\frac{\partial \rho u_{j}}{\partial t}+\nabla \rho u_{i} u_{j}=-\nabla P+\nabla \tau_{i j}+\rho g_{i}$
2. $\frac{\partial \rho u_{j}}{\partial t}+\nabla \rho k u_{i}=\nabla k\left(u_{i}+u_{j}^{T}\right)$

Tabel 1. Daftar Nilai Parameter yang Digunakan

\begin{tabular}{clcccc}
\hline Simbol & Keterangan & Nilai & Simbol & Keterangan & Nilai \\
\hline$\rho$ & Massa jenis udara & $1.2 \mathrm{~kg} / \mathrm{m}^{2}$ & $\mathrm{P}$ & Tekanan & $10 \mathrm{~Pa}$ \\
\hline $\mathrm{g}$ & $\begin{array}{l}\text { Percepatan } \\
\text { gravitasi }\end{array}$ & $10 \mathrm{~m} / \mathrm{s}^{2}$ & $\mathrm{k}$ & konduktivitas & $\begin{array}{c}0.026 \\
\mathrm{~W} / \mathrm{m}^{\circ} \mathrm{C}\end{array}$ \\
\hline$\mu$ & kekentalan zat & $\begin{array}{c}1.6 \times 10-5 \\
\mathrm{~kg} / \mathrm{m} \mathrm{s}\end{array}$ & & & \\
\hline
\end{tabular}

Selanjutnya dengan menggunakan teknik diskritisasi QUICK 7, maka model tersebut dapat diselesaikan dan disimulasikan secara numerik dengan bantuan software MATLAB.

\section{Metode}

Penelitian ini merupakan jenis penelitian terapan, yaitu penyelidikan yang hati-hati, sistematik dan terus menerus terhadap suatu masalah dengan tujuan digunakan untuk keperluan tertentu ${ }^{8}$. Metodologi yang digunakan di dalam analisis ini adalah perhitungan perpindahan panas dengan pemodelan metode Computational Fluid Dynamics (CFD) yaitu sebuah analisis sistem yang melibatkan aliran fluida, perpindahan kalor dan fenomena terkait

${ }^{7}$ Arif Fatahillah, "Analisis Numerik Profil Sedimentasi Pasir Pada Pertemuan Dua Sungai Berbantuan Software Fluent," KadikmA 5, no. 3 (December 1, 2014), https://jurnal.unej.ac.id/index.php/kadikma/article/view/1385.

8 Munir, "Karya Ilmiah: Penelitian Praktis Dan Strategis Dalam Rangka Penyiapan Seminar," accessed December 21, 2019, https://docplayer.info/41975336-Karya-ilmiah-penelitianpraktis-dan-strategis-dalam-rangka-penyiapan-seminar.html. 
dengan cara simulasi berbasis komputer ${ }^{9}$. Pada penelitian ini, peneliti melakukan berbagai tahapan penelitian yaitu membuat model aliran udara udara dalam optimasi teknologi pascapanen kemudian menyelesaikannya dengan menggunakan metode volume hingga. Setelah itu dilakukan diskritisasi dengan teknik QUICK untuk mendapatkan solusi umum berbentuk persamaan linier yang akan disimulasikan secara komputasi dengan menggunakan software MATLAB dan juga FLUENT. Berdasarkan hasil simulasi maka akan didapatkan data-data yang berguna dalam penarikan kesimpulan penelitian ini. Faktor utama yang akan menjadi fakus dalam penelitian ini adalah kecepatan aliran udara, tekanan udara, dan temperatur yang berpengaruh terhadap proses pengemasan buah tersebut.

\section{Hasil dan Diskusi}

Analisis simulasi sirkulasi udara pada proses pengemasan buah ini dibangun oleh persamaan momentum dan persamaan sistem, yang dilakukan penurunan rumus dengan menggunakan metode volume hingga serta diskritisasi menggunakan Teknik Diskritisasi Quadratic Upwind Interpolation Convertive Kinetis (QUICK) ${ }^{10}$. Diskritisasi QUICK pada penelitian ini karena menurut hasil yang dicapai dijamin stabil 11. Pada tahap selanjutnya disimulasikan dengan menggunakan software MATLAB dan FLUENT. Hasil simulasi yang digunakan untuk pengaruh temperatur awal yaitu $298^{\circ} \mathrm{K}$ berakibat temperatur tempat pengemasan konvergen menuju angka $282^{\circ} \mathrm{K}$ yang merupakan temperatur ideal dalam optimasi pengemasan buah. Sedangkan pada pengaruh ukuran tempat pengemasan kondisi ideal diperoleh jika volume kemasan berkisar antara 200-220 liter. Pada simulasi sistem tekanan udara untuk mencapai kondisi ideal, diperlukan tekanan awal sebesar $18 \mathrm{~Pa}$.

${ }^{9}$ R. Arévalo et al., "Estimation of Radiation Coupling Factors in Film Boiling Around Spheres by Mean of Computational Fluid Dynamics (Cfd) Tools," International Journal of Heat and Mass Transfer 78 (November 1, 2014): 84-89, https://doi.org/10.1016/j.ijheatmasstransfer.2014.06.063.

${ }^{10}$ Q. Qoriatul et al., "Analisis Model Matematika Pertukaran Panas Pada Fluida Di Heat Exchanger Tipe Shell and Tube Yang Digunakan Di PT. Pupuk Kaltim Tbk.," KadikmA 4, no. 1 (April 1, 2013), https://jurnal.unej.ac.id/index.php/kadikma/article/view/1050.

11 Tomi Tristono, "Model Perambatan Panas Arah Radial Benda-Benda Silindrik Multilayer," JURNAL AGRI-TEK : Jurnal Penelitian Ilmu-Ilmu Eksakta 11, no. 2 (n.d.): 68-76. 
(a)

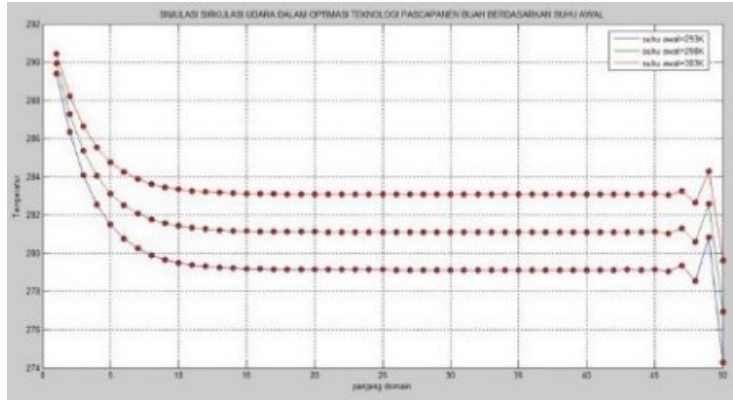

(b)

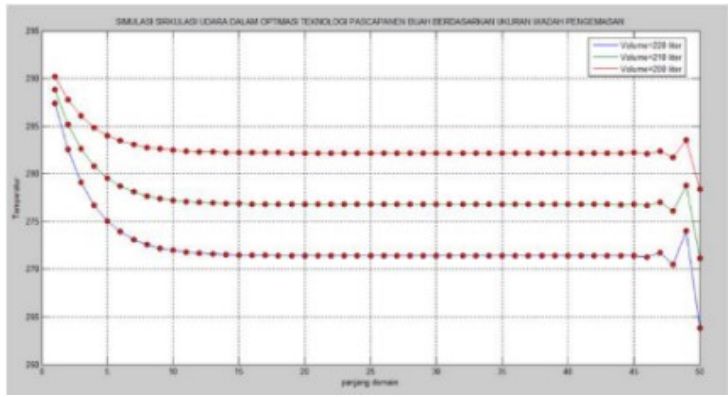

(c)

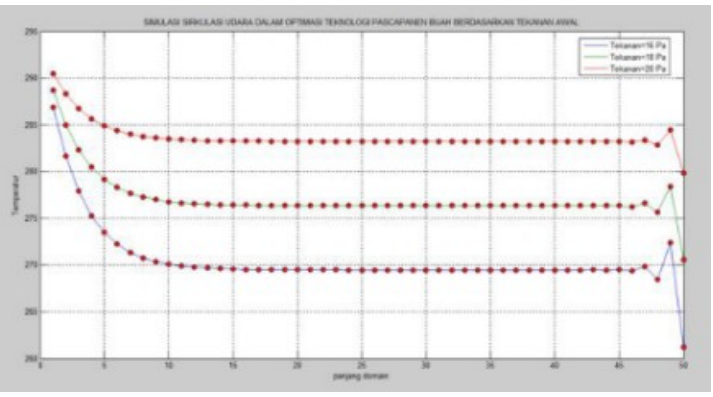

Gambar 1. (a) Grafik Simulasi Berdasarkan Suhu Awal, (b) Berdasarkan Ukuran tempat (c) Berdasarkan Tekanan Awal

Pada simulasi ini digunakan software FLUENT yaitu dengan cara menggambarkan objek yang akan diteliti dalam software Gambit untuk kemudian dilakukan simulasi dengan software FLUENT tersebut ${ }^{12}$. Dengan menggunakan software ini dapat diketahui parameter aliran dan perpindahan panas yang diinginkan seperti distribusi tekanan, kecepatan aliran, laju aliran massa, distribusi temperatur, dan pola aliran fluida yang terjadi dapat diketahui pada tiap titik yang terdapat dalam sistem yang dianalisa ${ }^{13}$. Pada penelitian ini digunakan untuk menganalisis bagaimana pengaruh posisi lubang udara, dan juga banyak lubang udara dalam tempat pengemasan tersebut.

12 Basuki Widodo, "Mathematical Modeling and Numerical Solution of Iron Corrosion Problem Based on Condensation Chemical Properties," IIUM Engineering Journal 12, no. 6 (2011), https://doi.org/10.31436/iiumej.v12i6.202.

${ }^{13}$ Syarip Syarip and Tri Nugroho, "Analisis Termohidrolik Fasilitas Eksperimen SAMOP (Reaktor Subkritik Produksi Isotop 99Mo)," Jurnal Pengembangan Energi Nuklir 19, no. 1 (July 15, 2017): 25-31, https://doi.org/10.17146/jpen.2017.19.1.3354. 
(a)
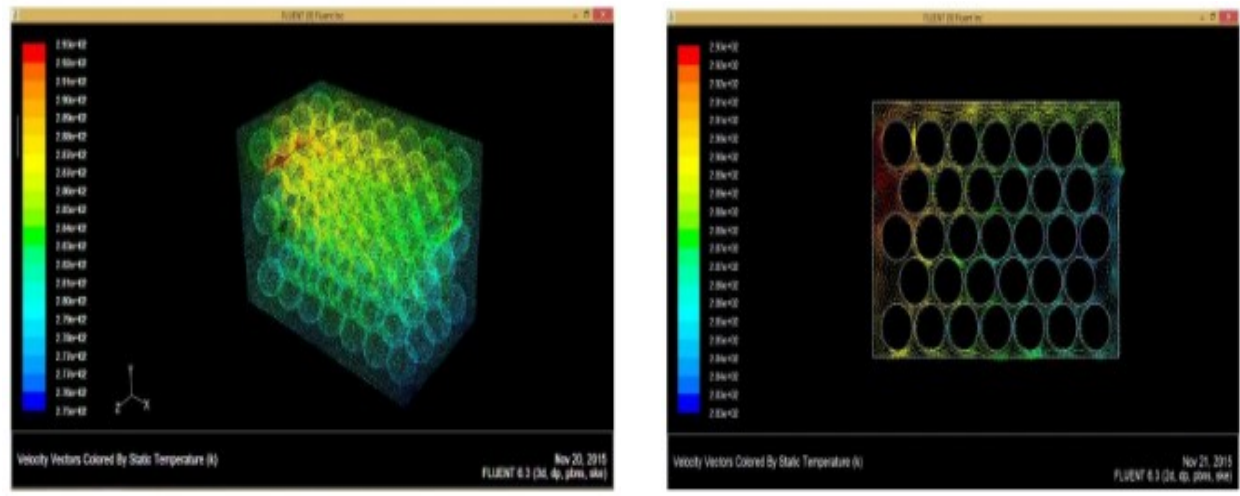

(b)
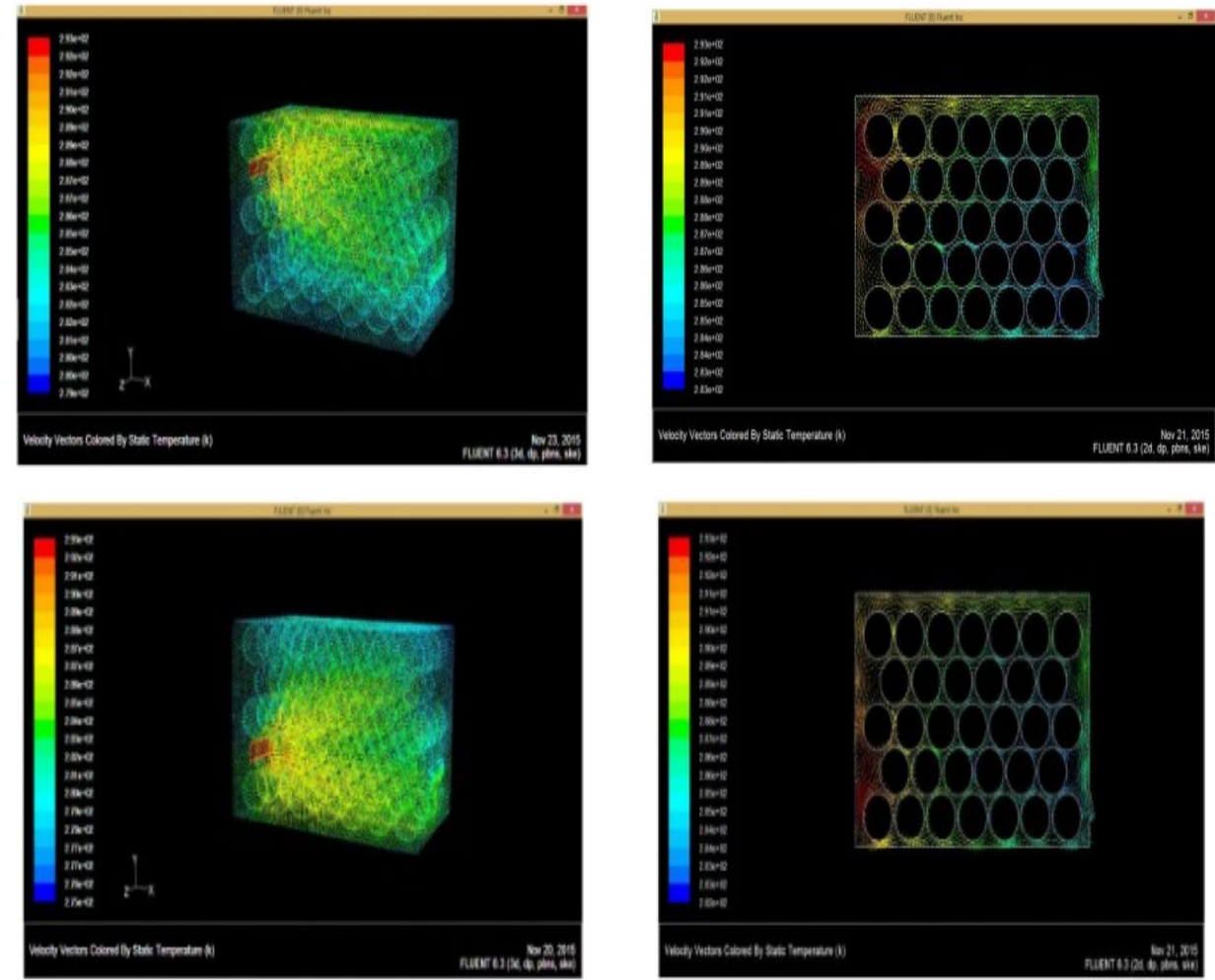

Gambar 2. Sirkulasi Udara Dalam Wadah Pengemasan Buah Berdasarkan

Posisi Lubang dalam 3D dan 2D; (a) lubang udara berada di atas; (b) lubang udara berada di atas dan di bawah; (c) lubang udara berada di bawah. 


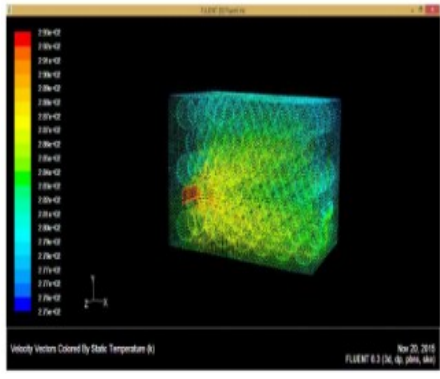

(a)

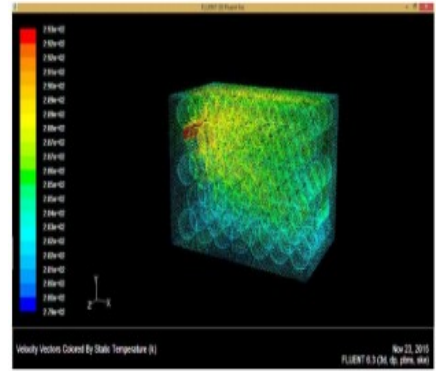

(b)

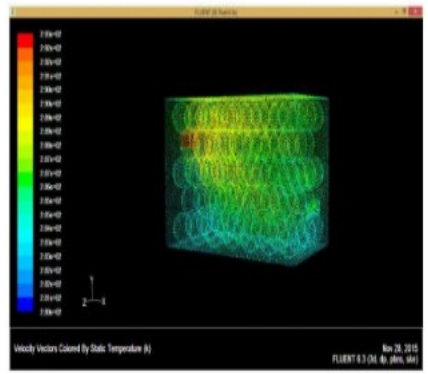

(c)

Gambar 3. Sirkulasi Udara Dalam Wadah Pengemasan Buah Berdasarkan

Banyaknya Lubang Udara dengan Posisi Lubang Berada di atas dan di bawah;(a) satu lubang udara; (b) dua lubang udara; (c) tiga lubang udara

Berdasarkan hasil simulasi menggunakan software FLUENT tersebut, didapatkan beberapa hal bahwa untuk mencapai temperatur yang ideal dalam proses pengemasan buah, maka lubang udara yang dibuat sebaiknya letaknya berseberangan dan pada posisi yang berbeda (atas dan bawah), dengan adanya perbedaan posisi itu tampak bahwa dalam simulasi didapatkan pemerataan aliran udara yang berakibat didapatnya temperatur ideal $\left(280^{\circ} \mathrm{K}\right)$ yang bisa memperawet kondisi buah yang ada dalam kotak pengemasan tersebut. Hasil simulasi yang lain menunjukkan jumlah lubang sirkulasi udara juga jangan terlalu banyak atau sedikit, pada simulasi ini kondisi yang ideal adalah dua lubang. Semakin banyak lubang sirkulasi yang dibuat, maka kondisi temperature juga semakin turun sampai $250^{\circ} \mathrm{K}$ (tidak ideal), demikian juga sebaliknya semakin sedikit lubang sirkulasi mengakibatkan 120temperatur semakin meningkat $320^{\circ} \mathrm{K}$ (tidak ideal) yang berakibat buah tersebut cepat matang dan membusuk.

\section{Kesimpulan}

Berdasarkan hasil analisis data dan pembahasan yang telah dilakukan, maka dapat diambil beberapa kesimpulan yaitu bahwa hubungan antara suhu awal dan tekanan udara dengan sirkulasi udara pada wadah pengemasan buah jeruk yaitu semakin besar suhu awal atau tekanan udara yang masuk maka suhu udara yang terbentuk di dalam wadah pengemasan akan semakin besar pula. Posisi lubang udara dan banyaknya lubang udara sangat mempengaruhi dalam optimalisasi sirkulasi udara, lubang dengan posisi atas dan bawah membantu dalam proses sirkulasi udara yang lebih merata, dan semakin banyak lubang udara akan meningkatkan suhu udara di dalam wadah pengemasan. 


\section{Daftar Pustaka}

Ambaw, Alemayehu, Mulugeta Delele, Thijs Defraeye, Quang Tri Ho, Umezuruike Opara, Bart Nicolaï, and P. Verboven. "The Use of CFD to Characterize and Design Post-Harvest Storage Facilities: Past, Present and Future." Computers and Electronics in Agriculture 93 (April 1, 2013): 184-94. https://doi.org/10.1016/j.compag.2012.05.009.

Andriani, Filli, Riswanti Sigalingging, and Saipul Bahri Daulay. "Kajian Aliran Udara Dan Suhu Pada Kemasan Komoditi Pepaya (Carica Papaya L) Menggunakan Teknik Computational Fluid Dynamics (CFD) (Study of Airflow and Temperature at Papaya Commodity Packaging Using Computational Fluid Dynamics (CFD) Technique)." Jurnal Rekayasa Pangan Dan Pertanian 6, no. 2 (September 27, 2018): 320-326-326.

Arévalo, R., D. Antúnez, L. Rebollo, and A. Abánades. "Estimation of Radiation Coupling Factors in Film Boiling Around Spheres by Mean of Computational Fluid Dynamics (Cfd) Tools." International Journal of Heat and Mass Transfer 78 (November 1, 2014): 84-89. https://doi.org/10.1016/j.ijheatmasstransfer.2014.06.063.

Fatahillah, Arif. "Analisis Numerik Profil Sedimentasi Pasir Pada Pertemuan Dua Sungai Berbantuan Software Fluent." KadikmA 5, no. 3 (December 1 , 2014). https://jurnal.unej.ac.id/index.php/kadikma/article/view/1385.

Food and Agriculture Org. Food Loss Preventation in Perishable Crops. Rome: The Food and Agriculture Organization, 1981.

Miskiyah, Miskiyah, Christina Winarti, and Wisnu Broto. "Kontaminasi Mikotoksin Pada Buah Segar Dan Produk Olahannya Serta Penanggulangannya." Jurnal Penelitian Dan Pengembangan Pertanian 29, no. 3 (December 5, 2016): 79-85. https://doi.org/10.21082/jp3.v29n3.2010.p79-85.

Munir. "Karya Ilmiah: Penelitian Praktis Dan Strategis Dalam Rangka Penyiapan Seminar." Accessed December 21, 2019. https://docplayer.info/41975336-Karya-ilmiah-penelitian-praktis-danstrategis-dalam-rangka-penyiapan-seminar.html.

Qoriatul, Q., Arif Fatahillah, D. Dafik, and Nurcholif Diah Sri Lestari. "Analisis Model Matematika Pertukaran Panas Pada Fluida Di Heat Exchanger Tipe Shell and Tube Yang Digunakan Di PT. Pupuk Kaltim Tbk." KadikmA 4, no. 1 (April 1, 2013). https://jurnal.unej.ac.id/index.php/kadikma/article/view/1050.

Siswadi -. "Penanganan Pasca Panen Buah-Buahan Dan Sayuran." Innofarm:Jurnal Inovasi Pertanian 6, no. 1 (September 1, 2012). http://ejurnal.unisri.ac.id/index.php/innofarm/article/view/250.

Syarip, Syarip, and Tri Nugroho. "Analisis Termohidrolik Fasilitas Eksperimen SAMOP (Reaktor Subkritik Produksi Isotop 99Mo)." Jurnal Pengembangan Energi Nuklir 19, no. 1 (July 15, 2017): 25-31. https://doi.org/10.17146/jpen.2017.19.1.3354.

Trisnawati, W., and Rubiyo. "Pengaruh Penggunaan Kemasan Dan Lama Penyimpanan Terhadap Mutu Buah Salak Bali." Jurnal Pengkajian Dan 
Pengembangan Teknologi Pertanian 7, no. 1 (August 11, 2014). https://doi.org/10.21082/jpptp.v7n1.2004.p\%p.

Tristono, Tomi. "Model Perambatan Panas Arah Radial Benda-Benda Silindrik Multilayer." JURNAL AGRI-TEK : Jurnal Penelitian IImu-IImu Eksakta 11, no. 2 (n.d.): 68-76.

Widodo, Basuki. "Mathematical Modeling and Numerical Solution of Iron Corrosion Problem Based on Condensation Chemical Properties." IIUM Engineering Journal 12, no. 6 (2011). https://doi.org/10.31436/iiumej.v12i6.202. 